\title{
Safety evaluation of Trikatu, a generic Ayurvedic medicine in Charles Foster rats
}

\author{
Debabrata Chanda', Karuna Shanker², Anirban Pal', Suaib Luqman'1, \\ Dnyaneshwar Umrao Bawankule', Dayanandan Mani1 and Mahendra Pandurang Darokar ${ }^{1}$ \\ ${ }^{1}$ Genetic Resources and Biotechnology Division, \\ ${ }^{2}$ Analytical Chemistry Division, Central Institute of Medicinal and Aromatic Plants (CSIR), Lucknow - 226015, India
}

(Received September 29, 2008; Accepted November 23, 2008)

\begin{abstract}
Chemical characterization and acute and sub-acute toxicity study of Trikatu, a generic herbal formulation of Indian system of medicine, was carried out in Charles Foster (CF) rats for safety profiling. In acute toxicity experiment, Trikatu at $2,000 \mathrm{mg} / \mathrm{kg}$ body weight once orally was well tolerated by the experimental animals (both male and female) and no changes were observed in mortality, morbidity, gross pathology, gain in weight, vital organ weight, hematological (total white blood cells (WBC) and red blood cells (RBC) count), biochemical parameters such as serum creatinine, serum glutamate oxaloacetate transaminase (SGOT), serum glutamate pyruvate transaminase (SGPT), serum lipid profile and tissue biochemical parameters such as reduced glutathione and malonaldehyde content as oxidative stress markers. In sub-acute experiment, Trikatu was administered at 5, 50 and $300 \mathrm{mg} / \mathrm{kg}$ body weight once daily for 28 days in female $\mathrm{CF}$ rats, and non-significant changes were found in most of the parameters studied such as acute experiment except significant increase in low density lipoprotein (LDL) cholesterol level at 50 and $300 \mathrm{mg} / \mathrm{kg}$ body weight, decrease in high density lipoprotein (HDL) cholesterol level at $300 \mathrm{mg} / \mathrm{kg}$ body weight, increase in SGPT activity at $50 \mathrm{mg} / \mathrm{kg}$ body weight and decrease in WBC count at $300 \mathrm{mg} / \mathrm{kg}$ body weight on $28^{\text {th }}$ day post treatment.
\end{abstract}

Key words: Trikatu, Safety evaluation, Oral toxicity, Herbal formulation

\section{INTRODUCTION}

Plants and plant-based deliverables are an important part of the health care system since ancient human civilization. The history of Indian health care system goes back to 5000 BC. Ancient Indian medical texts such as 'Charak Samhita' and 'Sushruta Samhita' were documented in about $1000 \mathrm{BC}$, where use of plants and poly herbal formulations were emphasized for health care and many of them are still in use in the Indian system of medicine (Mukherjee and Wahile, 2006). One such polyherbal formulation is Trikatu, a Sanskrit word meaning three acrids. In Ayurveda, black pepper (Piper nigrum Linn.), long pepper (Piper longum Linn.) and ginger (Zingiber officinalis Rosc.) are collectively known as Trikatu. It is prepared by mixing dried powder of fruits of black pepper, fruits of long pepper and rhizomes of ginger in the ratio of (1:1:1; $\mathrm{W} / \mathrm{W})$. The ancient documented Ayurvedic materia medica mentions these three drugs as essential ingredients of various prescriptions and formulations used for a wide range of diseases (Atal et al., 1981). The active principle of Trikatu is an alkaloid piperine or 1 - peperoyl piperidine (Fagen et al., 1995). Literature has revealed a number of pharmacological properties of piperine, and one of them is its anti-inflammatory activity (Lee et al., 1984). Apart from its Ayurvedic use, several studies have reported enhancement of blood levels of drugs such as vasicine, sparteine, phenytoin, propranolol, theopylline, sulphadiazine and tetracycline (Bano et al., 1987, 1991) reduction in the blood level of diclofenac sodium, rifampicin (Lala et al., 2004; Karan et al., 1999) when coadministered with Trikatu or piperine. Trikatu capsule $(500 \mathrm{mg})$ is available commercially in India and can be stored up to 2 years at room temperature. It has also the property of non-specific stimulation of immunity and also enhancement of vitality (Karan et al., 1999). All these aspects make Trikatu a drug of choice for several ailments in alternative medicine. However, the emergence of the safety issue of alternative medicine and increasing number of reports about the toxicity and/or adverse effects of Ayuurvedic and oth-

Correspondence: Debabrata Chanda (E-mail: chandapt@gmail.com) 


\section{Chanda et al.}

er alternative medicinal ingredients and formulations in the last couple of years (Ernst, 1998) severely affected the economics of herbal drugs. Data relating to toxicity of Trikatu as such is lacking. There are some reports on the toxicity on Piper longum (Shah et al., 1998). They studied the acute and chronic toxicity of ethanolic extract of Piper longum. L fruits and Cinnamonam zeylanicumI tree bark. But no report is available on the safety profile of Trikatu (a mixture of the dried fruits of black pepper, long pepper and rhizomes of ginger in the ratio of $1: 1: 1 \mathrm{~W} /$ W). This has led us to carry out the safety profiling of this commonly used Ayurvedic preparation in acute and subacute experiment in small experimental animals.

\section{MATERIALS AND METHODS}

\section{Chemicals used}

Malonaldehyde and reduced glutathione standard were purchased from Sigma Chemicals Ltd. (Bangalore, Karnataka, India). Diagnostic kits used such as serum glutamate oxaloacetate transaminase (SGOT), serum glutamate pyruvate transaminase (SGPT), total and high density lipoprotein (HDL) cholesterol, triglycerides and creatinine were obtained from Bayer Diagnostics (Leverkusen, Germany). Other common chemicals used in the whole experiment were of Guaranteed Reagent (GR) grade and obtained from E-Merck India Ltd..

\section{Animals}

Male and Female Charles Foster (CF) rats of 6 to 8 weeks of age weighing $(200 \pm 25 \mathrm{~g})$ were chosen for the study. The rats were maintained at $22 \pm 5^{\circ} \mathrm{C}$ with humidity control and also on an automatic dark and light cycle of $12 \mathrm{hr}$. The animals were fed with the standard rat feed and provided ad libitum drinking water.

\section{Preparation and quality assurance of Trikatu}

Trikatu was prepared following the procedure of Ayurvedic Formulary of India (2000). All three ingredients of formulation were cultivated in the research farm of our Institute. The specimens were deposited in the gene bank. Formulation was prepared in three small batches (3 x 200 g). The quality of each batch was assured using the liquid chromatography photo diode array mass spectrometer (LCPDA-MS) fingerprinting (Fig. 1). For LC-PDA-MS fingerprinting LC-system (Shimadzu, Kyoto, Japan) that consisted of a LC-20AD solvent delivery pumps, a DGU-20A degasser, a CTO-20A column oven and a SPD-M 20A photodiode array detector, and on-line mass spectrometer LCMS-2010EV (Shimadzu) was used. Data acquisition was performed on LC Solution 3.41 (Shimadzu). $100 \mathrm{mg}$ of Trikatu was sonicated $(50 \mathrm{~Hz})$ with methanol at $30^{\circ} \mathrm{C}$ for $30 \mathrm{~min}$ and filtered, concentrated under vacuum and re-dissolved in $5.0 \mathrm{ml}$ of methanol. Stock solution of piperine $(1 \mathrm{mg} / \mathrm{ml})$ was prepared and diluted to obtain a linearity curve for quantitative analysis. The solution was filtered with $0.45 \mu \mathrm{m}$ Nylon syringe filter (Millipore, Billerica, MA, USA) and $20 \mu \mathrm{l}$ was injection to high performance liquid chromatography (HPLC) (Stationary phase- Phenomenox $\mathrm{C}_{18} 4.6$ x $250 \mathrm{~mm}$ i.d. $5 \mu \mathrm{m}$; Mobile phase- Water: Methanol- 32:68; Flow rate $1.0 \mathrm{ml} / \mathrm{min}$; UV detection- $340 \mathrm{~nm}$ ). The column outlet was split by value (1:4) and only $250 \mu \mathrm{l} / \mathrm{min}$ of the column effluent was delivered into PDA and dual electron-spray ionization-atomic pressure chemical ionization (ESI-APCI) ion source of MS and the rest diverted towards waste. MS detection conditions were as follows: curved desolvation line (CDL) temperature and heat block temperature 250 and $480^{\circ} \mathrm{C}$, respectively, probe voltage $+4.5 \mathrm{kV}$, detector voltage $1.5 \mathrm{kV}, \mathrm{CDL}$ voltage $-20 \mathrm{~V}$ and Q-array Bios $50 \mathrm{~V}$. Nitrogen flow was at $1.5 \mathrm{l} / \mathrm{min}$. The Piperine was selected as a chemical marker. Absolute as well as relative concentration of piperine was considered for quality of each batch.

\section{Acute oral toxicity study}

Ten adult male CF rats of 6 to 8 weeks age were taken and divided into two groups of five animals each. Animals of group 1 were considered as control and treated with distilled water while animals of group 2 were taken as experimental wherein the animals were treated with aqueous suspension of Trikatu at $2,000 \mathrm{mg} / \mathrm{kg}$ body weight as a single oral dose. The animals were observed for morbidity and mortality at 1, 2, 4 and $6 \mathrm{hr}$ on the day of dosing and twice on the $7^{\text {th }}$ day. The body weights were recorded individually before and on $7^{\text {th }}$ day. The study was performed in accordance with Organisation for Economic Co-operation and Develop-ment (OECD) test guideline No. 423 (1987). Similar procedure was repeated for acute oral toxicity study with female CF rats where in 10 adult female rats were taken and experiment repeated as above.

\section{Sub-acute oral toxicity study}

In a repeated dose experiment, female rats were chosen because of their greater sensitivity (Ghosh, 1984) for which 20 rats were used and were divided into four groups, namely group 1, 2, 3 and 4 comprising five animals in each group. Animals of group 1 were kept as control and were treated with distilled water orally while animals of groups 2, 3 and 4 were treated with aqueous suspension of Trikatu at 5, 50 and $300 \mathrm{mg} / \mathrm{kg}$ body weight once orally for 28 days. Animals were observed 
Safety evaluation of 'Trikatu' Ayurvedic medicine

HPLC-PDA Profile
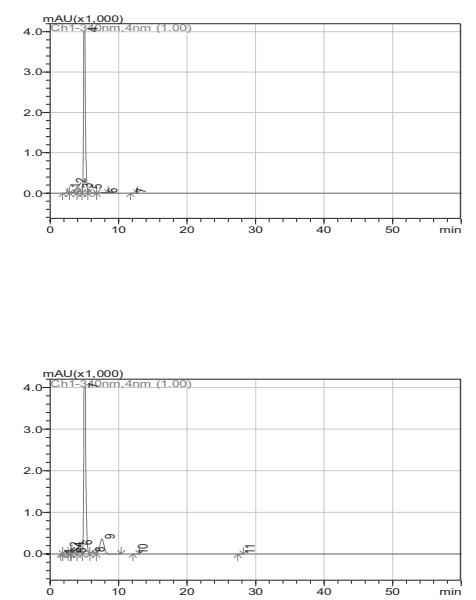

Zingiber officinale
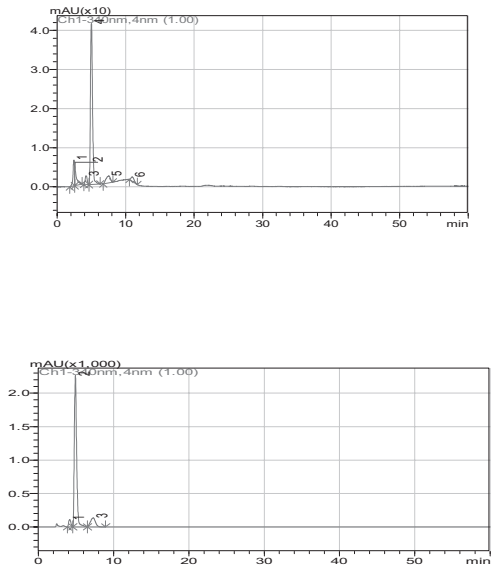

UV-Spectra of piperine

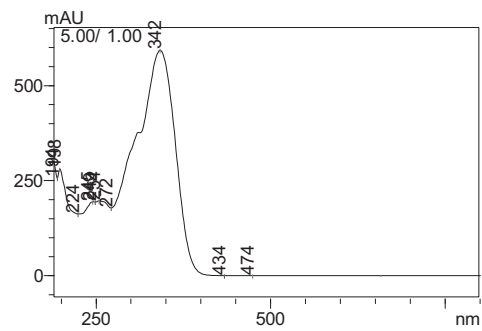

\section{Piper longum}

Piper nigrum

\section{Trikatu}

\section{LC-MS Profile}
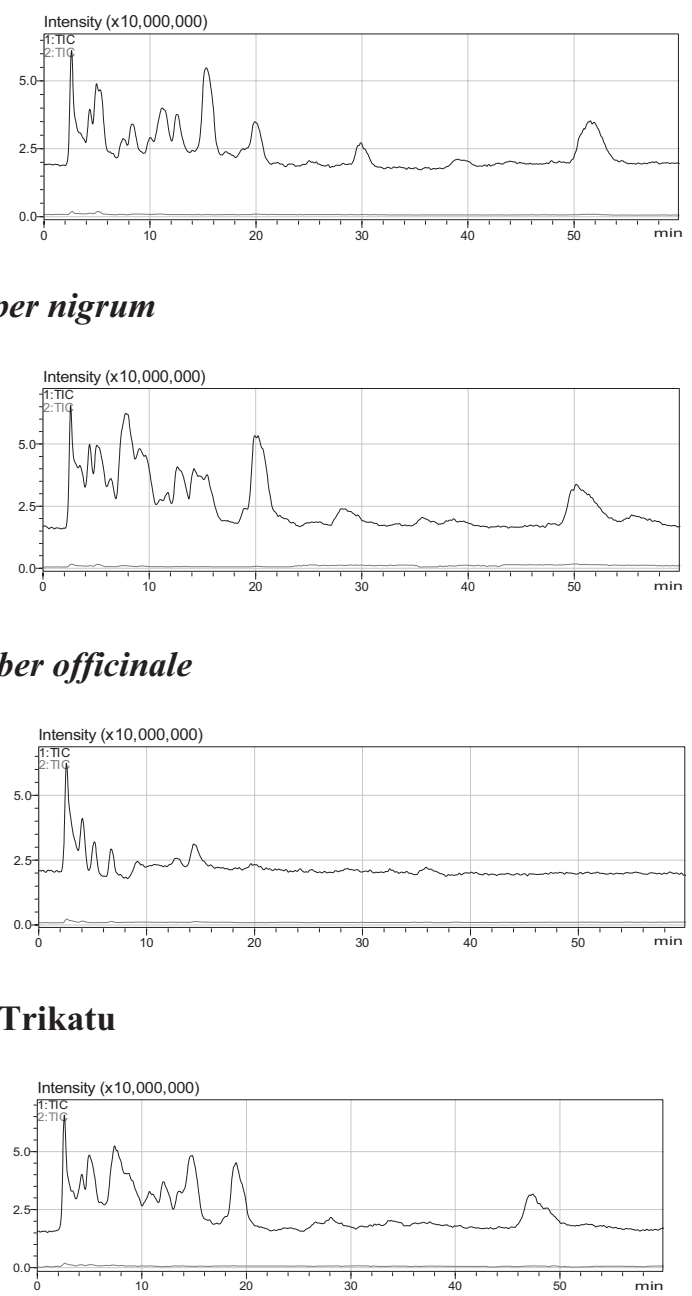

Mass-Spectra of piperine

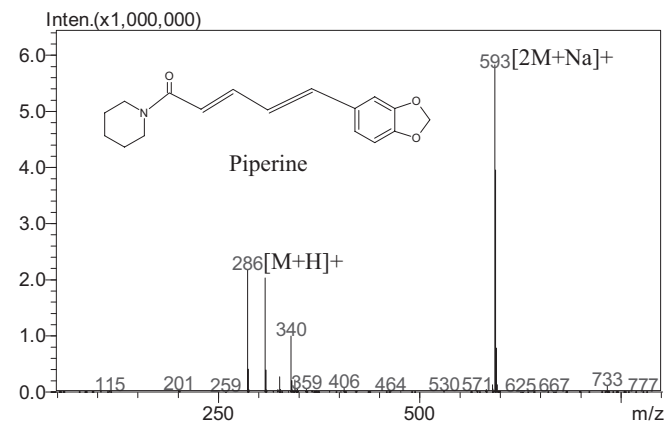

Fig. 1. Representative PDA chromatogram at $340 \mathrm{~nm}$ and mass chromatogram of Trikatu along with its all three ingredients. Characteristic UV and mass spectra of its active phytomarker i.e piperine. 


\section{Chanda et al.}

for mortality, appearance and any signs of intoxications. Body weights were recorded at initiation, $14^{\text {th }}$ day and on $28^{\text {th }}$ day. The experimental protocols were duly approved by the Institutional Animal Ethics Committee and were in accordance with OECD test guideline no. 407 (1987).

\section{In-life observation}

The animals were checked daily for mortality and any signs of ill health. A daily general case side clinical examination before and after commencement of the experiment was carried out including changes in skin, mucous membrane, eyes, occurrence of secretion and excretion and also responses such as lachrymation, pilo-erection respiratory patterns etc. Changes in gait, posture and response to handling were also recorded (Allan et al., 2007).

\section{Collection of samples}

Blood samples were collected from all animals of the acute experiment on $0^{\text {th }}$ and $7^{\text {th }}$ day and were used for analysis of different biochemical parameters. The animals of acute experiment were then sacrificed on $7^{\text {th }}$ days and were used for gross pathological study and measurement of differential organ weights.

Similarly, blood samples from all groups of animals of the sub-acute experiment were collected on $0^{\text {th }}, 14^{\text {th }}$ and $28^{\text {th }}$ days and were analyzed for different biochemical parameters. On completion, the animals were sacrificed and used for gross pathological examinations including weight of different organs such as liver, kidney, lung, heart, brain, spleen, adrenal, ovary etc. Small pieces of liver tissues from experimental and control groups were homogenized in normal saline solution (10\% homogenate). The homogenates thus obtained were centrifuged in a Biofuge Stratus at 3,000 rpm for $20 \mathrm{~min}$ at $4^{\circ} \mathrm{C}$ to obtain supernatants which were saved at $-20^{\circ} \mathrm{C}$ for biochemical assays.

\section{Hematological and biochemical analysis}

Neubawer's chamber was used to quantify the total red blood cells (RBC) and white blood cells (WBC) count. Serum biochemical parameters such as creatinine, SGOT, SGPT, total cholesterol, triglycerides, HDL and low density lipoprotein (LDL) cholesterol were estimated using kits from Bayer Chemicals Ltd. in a semi auto-analyzer, RA 50 chemistry system from Bayer Ltd.. Hepatic reduced glutathione content was estimated as described by Rizvi and Luqman (2002) based on the method of Beutler (1971). Oxidative stress marker level was estimated as described by Luqman and Rizvi (2006) based on Esterbauer and Cheeseman (1990) method by determining the level of malonaldehyde (MDA) in hepatic tissues.

\section{Statistical analysis}

Effect of aqueous suspension of Trikatu in experimental conditions was analyzed using software (Instat) to derive the results (Mean \pm S.E.). For non-parametric comparison, Turkey's test was employed using the same program.

\section{RESULTS}

The Trikatu formulation with piperine concentration $3.4 \% \mathrm{w} / \mathrm{w}$ (dry weight basis) was used for safety evaluation study. Exclusively piperine may not only be responsible for desired pharmacological actions, histopathological or biochemical effects of Trikatu. Therefore, the quality of the Trikatu formulation was demonstrated by reproducible LC-MS fingerprint developed using reverse phase separation and methanol-water as mobile phase (detailed methodology described in experimental section). The fingerprint of Trikatu along with its three constitutes are presented in Fig. 1. Based on the total ion current chromatogram (TIC chromatogram), Trikatu has been shown to have 165 characteristic peaks and that of $P$. longum, $P$. nigrum and $Z$. officinale were 119,155 and 155 peaks respectively with common presence of piperine.

\section{In life observations}

Rats treated with Trikatu showed no observable changes either in acute experiment (at 2,000 $\mathrm{mg} / \mathrm{kg}$ body weight) or sub-acute experiment (at 5, 50 and $300 \mathrm{mg} /$ $\mathrm{kg}$ body weight for 28 days). No morbidity or mortality was observed during the entire experimental period both in acute and sub-acute experiments. However, during the acute experiment, treated animals showed signs of inactivity and drowsiness for a period of thirty min and after two hr they were freed of these symptoms.

\section{Body weight}

In acute experiment, body weights were taken before and on the $7^{\text {th }}$ day after treatment with Trikatu at 2,000 $\mathrm{mg} / \mathrm{kg}$ body weight. Body weight of control group was comparable to that of experimental group in both male and female rats in acute study (Tables 1 and 2). In subacute experiment, body weights were taken on $0,14^{\text {th }}$ and $28^{\text {th }}$ day from all groups of animals. The absolute body weight was comparable in all experimental groups to that of control (Table 3).

\section{Differential organ weight}

Mean values of absolute and relative weights (per- 
Safety evaluation of 'Trikatu' Ayurvedic medicine

Table 1. Effect of Trikatu at $2,000 \mathrm{mg} / \mathrm{kg}$ body weight as a single dose orally on body weight and different biochemical and hematological parameters in male Charles Foster rat (Mean \pm S.E.). $n=5$. Non-significant changes were observed compared to control.

\begin{tabular}{|c|c|c|c|c|}
\hline \multirow[t]{2}{*}{ Parameters Studied } & \multicolumn{2}{|c|}{$0^{\text {th }}$ day } & \multicolumn{2}{|c|}{$7^{\text {th }}$ day } \\
\hline & Control & Experimental & Control & Experimental \\
\hline Body wt. (g) & $183.37 \pm 5.54$ & $191.15 \pm 4.35$ & $205.36 \pm 7.09$ & $207.69 \pm 5.00$ \\
\hline Serum creatinine $(\mathrm{mg} / \mathrm{dl})$ & $0.37 \pm 0.04$ & $0.35 \pm 0.06$ & $0.43 \pm 0.02$ & $0.53 \pm 0.08$ \\
\hline Total cholesterol (mg/dl) & $78.50 \pm 3.67$ & $91.04 \pm 9.58$ & $76.27 \pm 3.12$ & $84.11 \pm 3.69$ \\
\hline HDL - cholesterol (mg/dl) & $55.28 \pm 4.23$ & $60.73 \pm 7.46$ & $55.70 \pm 3.66$ & $59.51 \pm 2.94$ \\
\hline Serum Triglycerides (mg/dl) & $66.94 \pm 9.33$ & $85.45 \pm 11.75$ & $61.50 \pm 6.33$ & $69.16 \pm 9.45$ \\
\hline LDL - cholesterol (mg/dl) & $9.84 \pm 1.92$ & $13.22 \pm 3.07$ & $8.30 \pm 3.71$ & $10.77 \pm 1.86$ \\
\hline SGOT (U/l) & $64.87 \pm 5.66$ & $61.71 \pm 5.52$ & $76.61 \pm 4.13$ & $85.04 \pm 5.87$ \\
\hline SGPT (U/l) & $18.20 \pm 0.38$ & $18.00 \pm 0.65$ & $21.70 \pm 0.82$ & $24.90 \pm 1.32$ \\
\hline Total WBC (thousands/mm³) & $7.75 \pm 0.64$ & $10.22 \pm 0.38$ & $11.28 \pm 1.15$ & $13.47 \pm 1.21$ \\
\hline Total RBC (millions/mm³) & $14.18 \pm 0.26$ & $18.34 \pm 1.74$ & $24.95 \pm 1.74$ & $24.42 \pm 2.54$ \\
\hline Reduced GSH ( $\mu \mathrm{M} / \mathrm{mg}$ protein) & & & $0.42 \pm 0.03$ & $0.49 \pm 0.04$ \\
\hline Malonaldehyde (p mol/mg protein) & & & $8.24 \pm 1.27$ & $5.40 \pm 0.04$ \\
\hline
\end{tabular}

Table 2. Effect of trikatu at $2,000 \mathrm{mg} / \mathrm{kg}$ body weight as a single dose orally on body weight and different biochemical and hematological parameters in female Charles Foster rat (Mean \pm S.E.). $n=5$. Non-significant changes were observed compared to control.

\begin{tabular}{|c|c|c|c|c|}
\hline \multirow[t]{2}{*}{ Parameters Studied } & \multicolumn{2}{|c|}{$0^{\text {th }}$ day } & \multicolumn{2}{|c|}{$7^{\text {th }}$ day } \\
\hline & Control & Experimental & Control & Experimental \\
\hline Body wt. (g) & $196.72 \pm 6.27$ & $206.90 \pm 8.34$ & $187.14 \pm 6.79$ & $206.41 \pm 8.34$ \\
\hline Serum creatinine $(\mathrm{mg} / \mathrm{dl})$ & $0.94 \pm 0.044$ & $0.90 \pm 0.069$ & $0.80 \pm 0.233$ & $0.78 \pm 0.083$ \\
\hline Total cholesterol (mg/dl) & $56.34 \pm 3.815$ & $52.86 \pm 4.570$ & $54.43 \pm 4.684$ & $53.74 \pm 3.703$ \\
\hline HDL - cholesterol (mg/dl) & $25.40 \pm 1.791$ & $19.83 \pm 1.278$ & $26.80 \pm 2.432$ & $31.96 \pm 1.402$ \\
\hline Serum Triglycerides (mg/dl) & $55.36 \pm 11.95$ & $51.09 \pm 5.53$ & $43.85 \pm 8.43$ & $43.98 \pm 11.89$ \\
\hline LDL - cholesterol (mg/dl) & $19.87 \pm 4.546$ & $22.81 \pm 2.795$ & $18.86 \pm 3.907$ & $12.98 \pm 4.389$ \\
\hline SGOT (U/1) & $54.67 \pm 7.31$ & $67.20 \pm 5.36$ & $51.88 \pm 1.93$ & $63.48 \pm 3.78$ \\
\hline SGPT (U/1) & $18.69 \pm 1.53$ & $19.76 \pm 1.22$ & $20.40 \pm 1.02$ & $21.06 \pm 1.84$ \\
\hline Total WBC (thousands $/ \mathrm{mm}^{3}$ ) & $8.55 \pm 0.96$ & $11.42 \pm 1.38$ & $9.50 \pm 1.07$ & $10.20 \pm 1.04$ \\
\hline Total RBC (millions/mm³) & $1.25 \pm 0.16$ & $1.05 \pm 0.07$ & $1.47 \pm 0.07$ & $1.44 \pm 0.20$ \\
\hline Reduced GSH ( $\mu \mathrm{M} / \mathrm{mg}$ protein) & & & $0.15 \pm 0.02$ & $0.17 \pm 0.03$ \\
\hline Malonaldehyde (p mol/mg protein) & & & $7.39 \pm 1.63$ & $6.80 \pm 1.22$ \\
\hline
\end{tabular}

cent body weight) of different vital organs such as adrenal, kidney, liver, lung, brain, heart, spleen, testis, ovary etc. of treatment group were found to be comparable to that of control group in acute experiment (Figs. 2 and 3). Likewise non-significant changes were observed in both absolute and relative organ weights in sub-acute exper- iment with Trikatu when mean values of different treatment groups were compared to that of control (Fig. 4).

\section{Hematological and biochemical parameters}

Trikatu at $2,000 \mathrm{mg} / \mathrm{kg}$ body weight did not induce any significant change in total $\mathrm{RBC}$ and $\mathrm{WBC}$ count in 
D. Chanda et al.

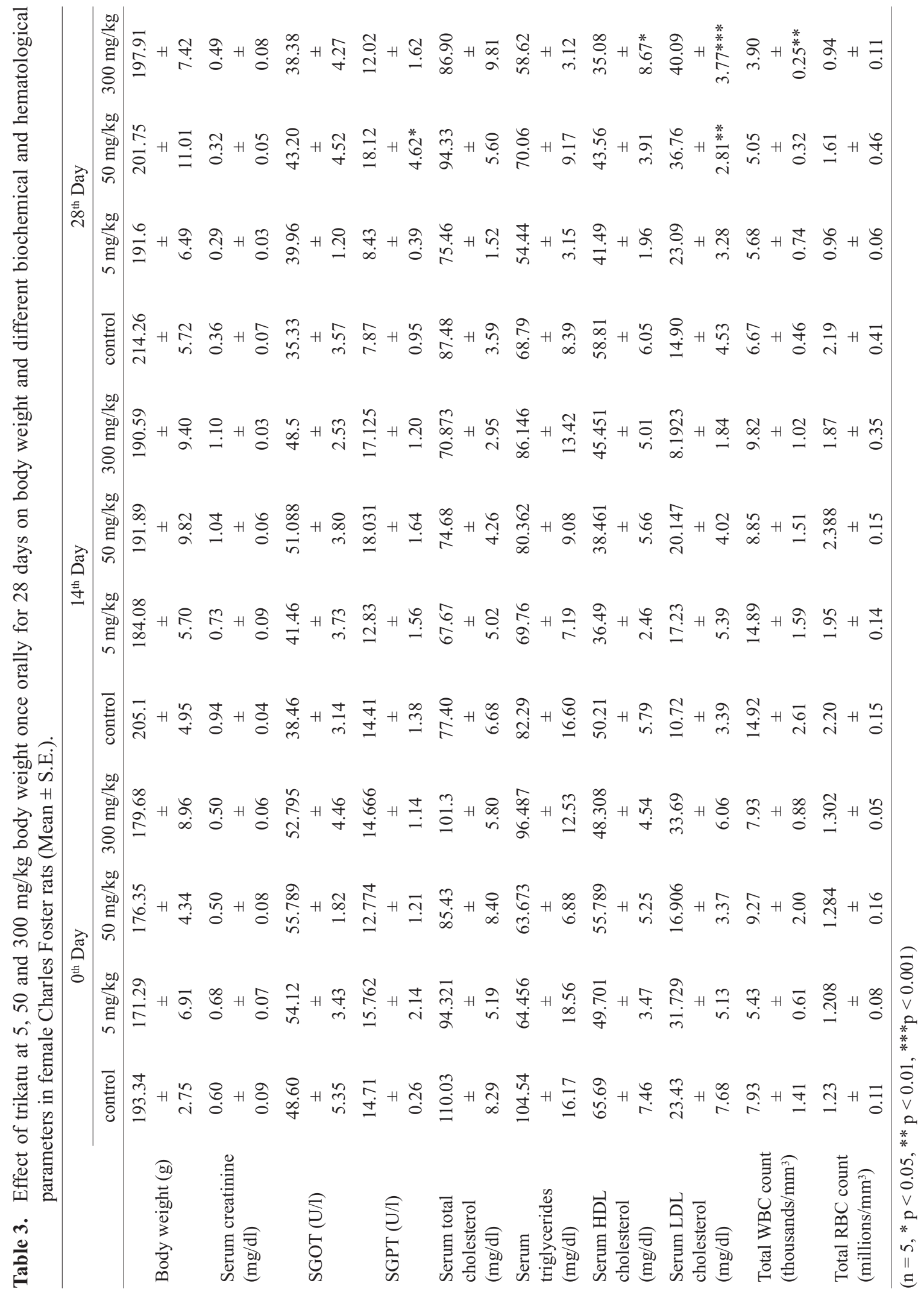




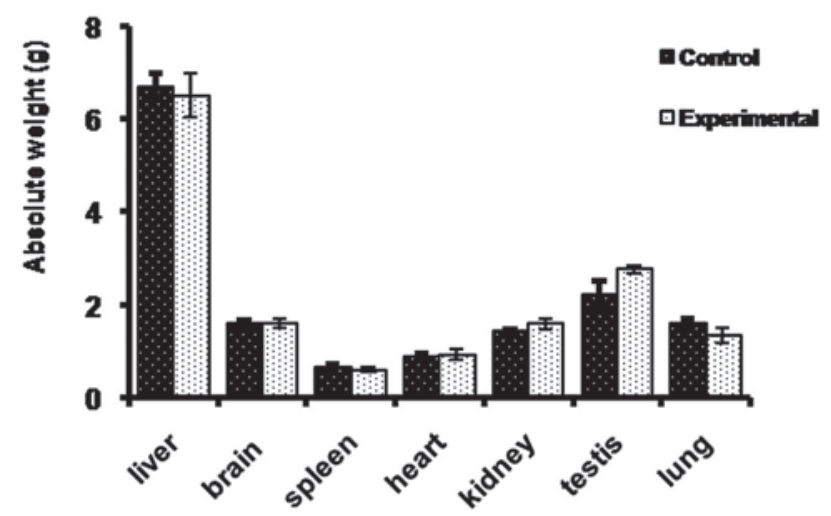

Different vital organ

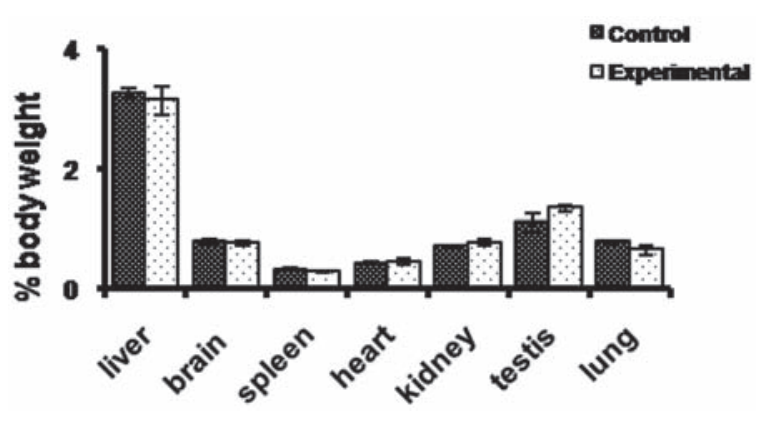

Differential organs

Fig. 2. Effect of trikatu at $2,000 \mathrm{mg} / \mathrm{kg}$ body weight as a single oral dose on differential organ weight (absolute and relative weight) in male $\mathrm{CF}$ rat (Mean \pm S.E.). $\mathrm{n}=5$. Non-significant changes were observed compared to control.
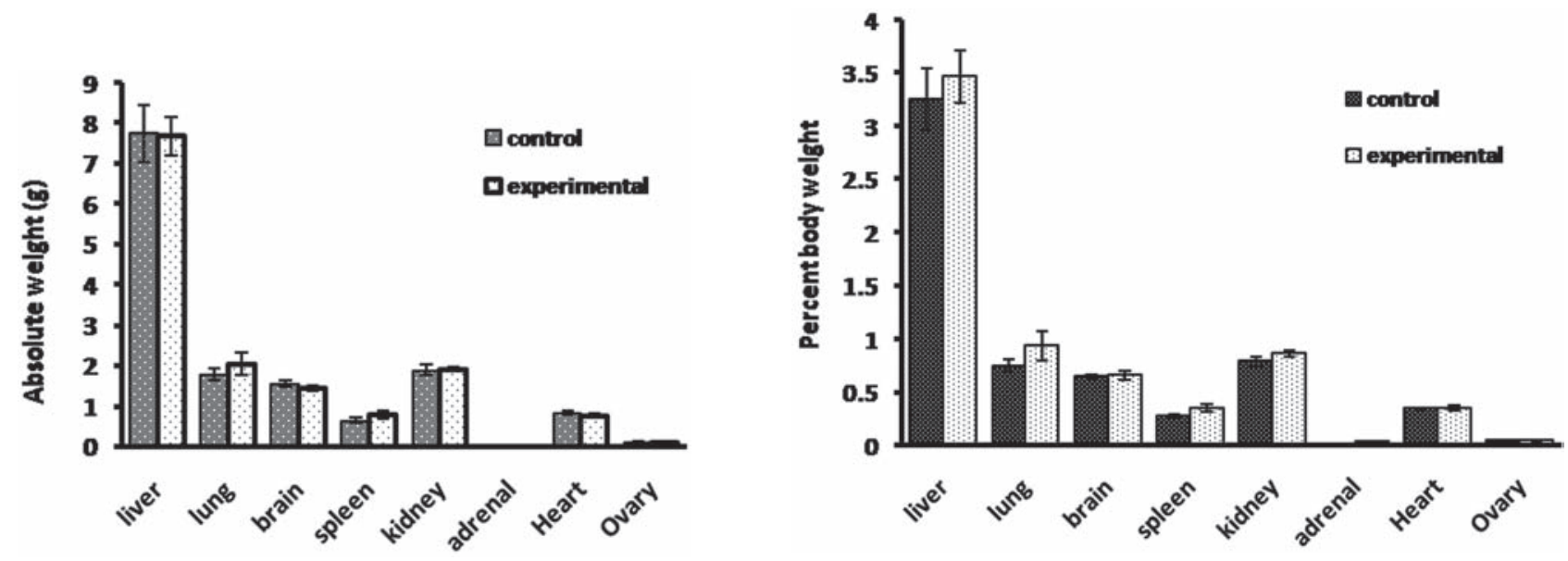

Fig. 3. Effect of trikatu at $2,000 \mathrm{mg} / \mathrm{kg}$ body weight as a single oral dose on differential organ weight (absolute and relative weight) in female $C F$ rat (Mean \pm S.E.). $n=5$. Non-significant changes were observed compared to control.
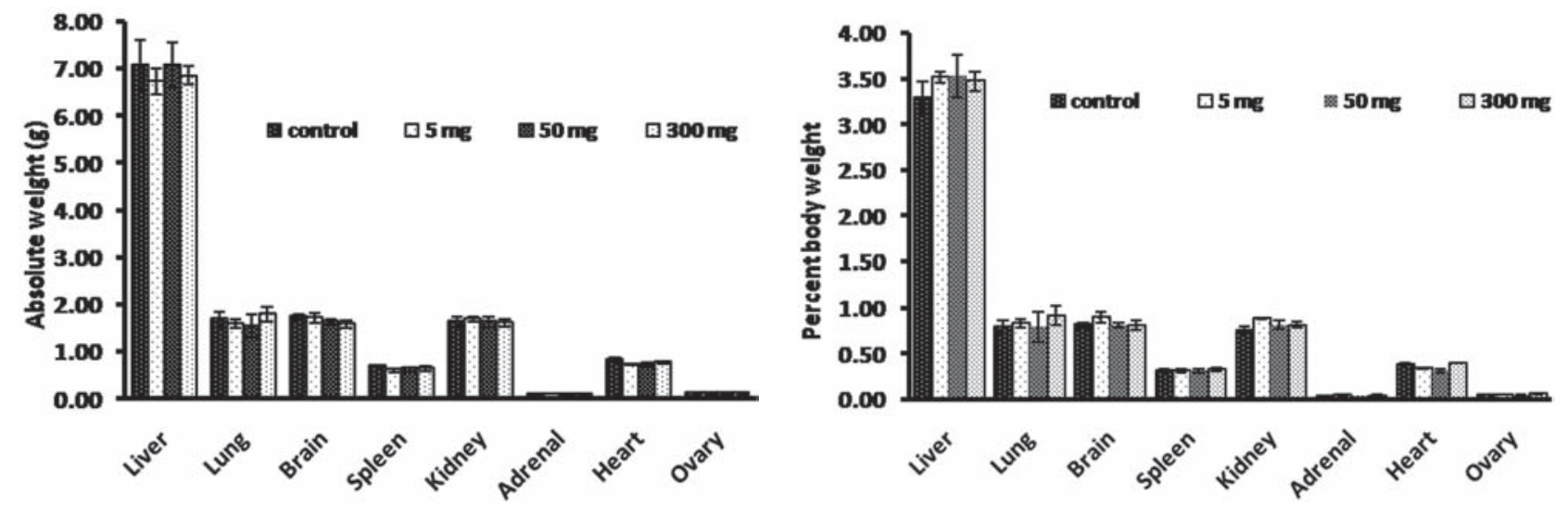

Fig. 4. Effect of trikatu at 5,50 and $300 \mathrm{mg} / \mathrm{kg}$ body weight once orally for 28 days on differential organ weight (absolute and relative weight) in female $\mathrm{CF}$ rat (Mean \pm S.E.). $n=5$. Non-significant changes were observed compared to control. 
either of the sex studied. Similarly, acute experiment with Trikatu showed no observable changes in biochemical parameters such as serum creatinine, SGOT, SGPT and serum lipid indices such as total cholesterol, HDL and LDL cholesterol and triglycerides and tissue biochemical parameters (Tables 1 and 2). In sub-acute experiment with Trikatu at 5,50 and $300 \mathrm{mg} / \mathrm{kg}$ body weight once orally for 28 days, no changes were observed in total $\mathrm{RBC}$ and WBC count in all experimental groups compared to control except animals of group $4(300 \mathrm{mg} / \mathrm{kg}$ body weight) which showed significant decrease in total WBC count on $28^{\text {th }}$ day (Table 3 ). Biochemical parameters studied in sub-acute experiments such as serum creatinine, triglycerides, total cholesterol and SGOT showed non-significant changes (Table 3). However, LDL, HDL cholesterol level and SGPT activity showed significant changes in the experimental group. Group of animals treated with Trikatu at $300 \mathrm{mg} / \mathrm{kg}$ body weight showed significant decrease in HDL cholesterol level on $28^{\text {th }}$ day (Table 3) while significant increases in LDL cholesterol level were observed in animals treated with Trikatu at 50 and $300 \mathrm{mg} / \mathrm{kg}$ body weight on the $28^{\text {th }}$ day compared to respective controls (Table 3 ). SGPT showed significant increase in activity in the group of animals treated with Trikatu at $50 \mathrm{mg} / \mathrm{kg}$ body weight on $28^{\text {th }}$ day (Table 3) although no change in activity was observed at higher dose (300 mg/kg body weight). Additionally, liver tissue homogenates from control and experimental groups of animals were analyzed for study of oxidative stress to the tissue. Non-significant changes in lipid peroxidation level were observed in acute (Tables 1 and 2) and subacute experiment (Fig. 5). Reduced gluthione content also showed non-significant changes in both acute (Tables 1 and 2) and sub-acute experiments except the group of animals receiving Trikatu at $300 \mathrm{mg} / \mathrm{kg}$ body weight, which showed significant increase in reduced glutathione content (Fig. 6) compared to control.

\section{DISCUSSION}

The efficacy of herbal formulation is always in question due to paucity of methods to ensure the reproducible quality. Since the activity of herbal formulations are not because of single compounds, therefore the quality of the herbal formulation cannot be ensured by quantitative measurement of single, two or three marker compounds. The complex nature of phytochemicals is the main challenge. We experienced that technique such as HPLC fingerprint based on photo diode detection is unable to differentiate Piper longum, Piper nigrum and Zingiber officinale in Trikatu (Fig. 1). The compounds having no

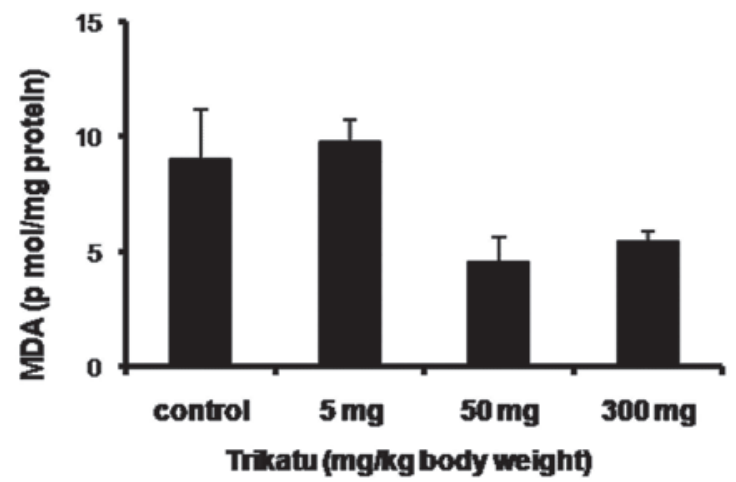

Fig. 5. Effect of trikatu at 5,50 and $300 \mathrm{mg} / \mathrm{kg}$ on hepatic MDA content ( $\mathrm{p} \mathrm{mol} / \mathrm{mg}$ protein) in CF female rats. $\mathrm{n}=5$. Non-significant change was observed compared to control.

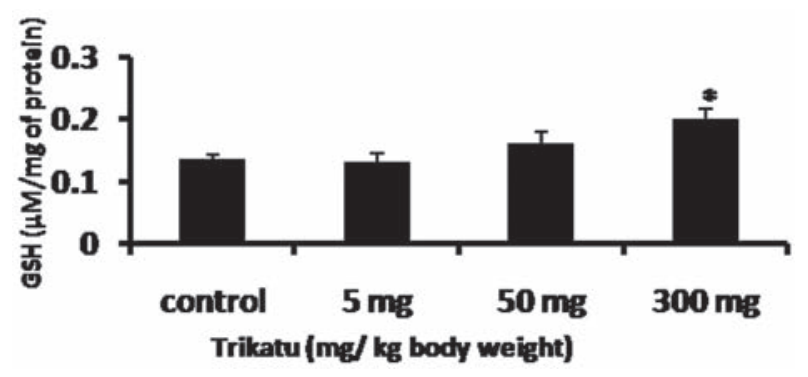

Fig. 6. Effect of trikatu at 5,50 and $300 \mathrm{mg} / \mathrm{kg}$ on hepatic reduced glutathione content ( $\mu \mathrm{mol} / \mathrm{mg}$ of protein) in CF female rats (Mean \pm S.E.). $(n=5, * \mathrm{p}<0.05$ compared to control).

chromophoric groups are not detected by this method. To overcome difficulties, we developed a method to generate the LC-MS fingerprint (Fig. 1), which covers the detection of compounds having mass range of up to $800 \mathrm{amu}$ irrespective of their chemical nature. The characteristic UV and mass-spectra of one of the marker compounds of Trikatu is presented in Fig. 1. TIC chromatogram of Trikatu showed 165 characteristic peaks under experimental conditions of separation and MS detection while individual ingredients of the formulation i.e. P. longum, P. nigrum and $Z$. officinale showed 119, 155 and 155 characteristic TIC peaks. This showed the diverse chemical nature of all three plants with common presence of piperine. Therefore, piperine as a single active marker for quality assurance of Trikatu may not be appropriate. The TIC chromatogram (MS-fingerprint) is the better choice to define the quality of the Trikatu formulation. The quality of the various batches was ensured by considering the mean area 
Safety evaluation of 'Trikatu' Ayurvedic medicine

under each peak and computed statistically by non-parametric test $(\mathrm{p}<0.05)$.

The test drug Trikatu was administered orally to CF rat at acute $(2,000 \mathrm{mg} / \mathrm{kg}$ body weight as a single dose $)$ and sub-acute doses at 5,50 and $300 \mathrm{mg} / \mathrm{kg}$ body weight once daily for 28 days with the objective of determining the safety limit in our experimental condition so that data can be extrapolated to a human patient (Paget and Barnes, 1964). No mortality or morbidity was observed throughout the experimental period. Non-significant changes were observed in absolute body weight in both acute and sub-acute experiments. Similarly, no changes were observed in vital organ weight measurement both in absolute and relative terms. Hematological parameters showed non-significant changes except decrease in total WBC count on $28^{\text {th }}$ day at $300 \mathrm{mg} / \mathrm{kg}$ body weight in subacute experiment. Likewise, most of the serum biochemical parameters like SGOT, serum creatinine, total cholesterol, and triglycerides exhibited non-significant changes except significant increase in LDL cholesterol level at 50 and $300 \mathrm{mg} / \mathrm{kg}$ body weight, decrease in HDL cholesterol level at $300 \mathrm{mg} / \mathrm{kg}$ body weight, increase in SGPT activity at $50 \mathrm{mg} / \mathrm{kg}$ body weight on $28^{\text {th }}$ day post treatment. Trikatu at $2,000 \mathrm{mg} / \mathrm{kg}$ body weight did not show any changes in hepatic reduced glutathione content and oxidative stress indices (Tables 1 and 2). Trikatu at 300 $\mathrm{mg} / \mathrm{kg}$ body weight for 28 days significantly increased the reduced glutathione content of hepatic tissue compared to control (Fig. 6) although non-significant increase in reduced glutathione content was observed in lower doses of Trikatu in sub-acute experiment. MDA content was estimated as a oxidative stress marker and non-significant changes were observed both in acute and sub acute experiment with Trikatu (Fig. 5). This is the first report of the safety profile of chemically characterized Trikatu, a polyherbal formulation of much use in Ayurvedic Medicine. However, there are reports about the potential pharmacological and toxicological effects of piperine as such and some herbs containing piperine. Role of piperine in reversal of beryllium induced adverse effects was studied in rats and found that piperine at $10 \mathrm{mg} / \mathrm{kg}$ body weight was quite effective in the remediation of toxic response (Nirala et al., 2008). Similarly, piperine (1, 10 and 50 $\mu \mathrm{g} / \mathrm{ml}$ ) was found effective in cadmium induced alterations in murine thymocytes pertaining to its anti-oxidative, anti-apoptotic and restorative activity (Pathak and Khandelwal, 2006). They found it to be a potent immunostimulant in immunocompromised murine thymocytes. Acute and sub-acute toxicity of piperine in mice, rats and hamsters was also carried out (Piyachaturawat et al., 1983). The workers found that piperine is acute- ly toxic to mice, rat and hamsters and acute LD50 value for mice was $15.1 \mathrm{mg} / \mathrm{kg}$ body weight as i.v. dose. The experimental animals died in sub-acute experiment within 1 to 3 days due to multi organ damage. Daware et al. (2000) reported the potential reproductive toxicity of piperine in swice albino mice. Piperine at 10 and $20 \mathrm{mg} / \mathrm{kg}$ body weight produce decreased mating performance and fertility, loss of implantations including histopathological changes in the ovary and uterus. Similarly, piperine was also evaluated for immunotoxicological potential in Swice albino mice (Dogra et al., 2004). Piperine at $1.12 \mathrm{mg} / \mathrm{kg}$ body weight did not show any immunotoxic response but showed significant toxicity at higher doses ( 2.25 and $4.5 \mathrm{mg} / \mathrm{kg}$ body weight for 5 days) producing decrease in the weight of spleen, thymus and mesenteric lymph node, reduction in lymphocyte count so also serum antibody titer and cellular immune response. Shah et al. (1998) studied the acute and chronic toxicity of ethanolic extracts of Piper longum fruits and Cinnamomum zeylanicum bark containing piperine as one of the active constituents. These herbs are used as a spice and also as an ingredient in several alternative preparations. The workers recorded morphological, hematological changes including body weights and vital organ weights (Shah et al., 1998). These extracts produced no mortality or morbidity during the study period. However, there was a decrease in liver weight, increase in lung and spleen weight and also a fall in hemoglobin level in chronic toxicity study. In a parallel type of study with Bacopa monnieri leaf enriched extract at acute and sub-acute level in SpragueDawley rats, it was observed that the extract is well tolerated at $500 \mathrm{mg} / \mathrm{kg}$ body weight for 14 days and also at 85,210 and $500 \mathrm{mg} / \mathrm{kg}$ body weight for 90 days (Allan et al., 2007). However, there is no report on the toxicity profile of Trikatu. We have used Trikatu, which is chemically defined and fingerprinted for the safety profiling. Trikatu as such had no effect on the morbidity and mortality in our experiment including body weight, vital organ weight and major biochemical parameters studied. However, significant increase in LDL cholesterol level at 50 and 300 $\mathrm{mg} / \mathrm{kg}$ body weight, decrease in HDL cholesterol level at $300 \mathrm{mg} / \mathrm{kg}$ body weight, increase in SGPT activity at 50 $\mathrm{mg} / \mathrm{kg}$ body weight and decrease in WBC count at 300 $\mathrm{mg} / \mathrm{kg}$ body weight on $28^{\text {th }}$ day was observed in sub-acute study.

From our observations, it can be concluded that Trikatu at $2,000 \mathrm{mg} / \mathrm{kg}$ body as a single dose orally in both male and female CF rats and at $5 \mathrm{mg} / \mathrm{kg}$ body weight once orally for 28 days is well tolerated by adult female CF rats. 


\section{ACKNOWLEDGMENT}

Authors are thankful to Council of Scientific and Industrial Research (CSIR), New Delhi for financial support.

\section{REFERENCES}

Allan, J.J., Damodaran, A., Deshmukh, N.S., Goudar, K.S. and Amit, A. (2007): Safety evaluation of a standardized phytochemical composition extracted from Bacopa monnieri in Sprague-Dawley rats. Food Chem. Toxicol., 45, 1928-1937.

Atal, C.K., Zutshi, U. and Rao, P.G. (1981): Scientific evidence on the role of Ayurvedic herbals on bioavailability of drugs. J. Ethnopharmacol., 4, 229-232.

Bano, G., Amla, V., Raina, R.K., Zutshi, U. and Chopra, C.L. (1987): The effect of piperine on pharmacokinetics of phenytoin in healthy volunteers. Planta Med., 53, 568-569.

Bano, G., Raina, R.K., Zutshi, U., Bedi, K.L., Johri, R.K. and Sharma, S.C. (1991): Effect of piperine on bioavailability and pharmacokinetics of propranolol and theophylline in healthy volunteers. Eur. J. Clin. Pharmacol., 41, 615-617.

Beutler, E. (1971): Reduced glutathione (GSH) In Beutler, E. (ed.) Red Cell Metabolism. pp.103-105, Grunne and Straton, New York.

Daware, M.B., Mujumdar, A.M. and Ghaskadbi, S. (2000): Reproductive toxicity of piperine in Swiss albino mice. Planta Med., 66, 231-236.

Dogra Ram, K.S., Khanna, S. and Shanker, R. (2004): Immunotoxicological effects of piperine in mice Toxicology, 196, 229-236.

Ernst, E. (1998): Harmless Herbals? A review of the recent literature. Am. J. Med., 104, 170-178.

Esterbauer, H. and Cheeseman, K.H. (1990): Determination of aldehydic lipid peroxidation products: Malonaldehyde and 4-hydroxynonenal. Methods Enzymol., 186, 407-421.

Fagen, H.J., Kolen, E.P. and Hussong, R.V. (1995): Spice analysis, spectrophotometric method for determining piperine in oleoresins of black pepper. J. Agric. Food Chem., 3, 860-862.

Ghosh, M.N. (1984): In Fundamentals of Experimental Pharmacology (1 $1^{\text {st }}$ Edition), p.2, Scientific Book Agency, Kolkata.

Karan, R.S., Bhargava, V.K. and Garg, S.K. (1999): Effect of Trikatu, an Ayurvedic prescription, on the pharmacokinetic profile of rifampicin in rabbits. J. Ethnopharmacol., 64, 259-264.

Lala, L.G., D'Mello, P.M. and Naik, S.R. (2004): Pharmacokinetic and pharmacodynamic studies on interaction of "Trikatu" with diclofenac sodium. J. Ethnopharmacol., 91, 277-280.

Lee, K.B., Shin, K.H. and Wan, W.S. (1984): Central nervous system depressant and anti-inflammatory activity of piperine. Archives of Pharmacal Research, 1, 127-132.

Luqman, S. and Rizvi, S.I. (2006): Protection of lipid peroxidation and carbonyl formation in proteins by capsaicin in human erythrocytes subjected to oxidative stress. Phytother. Res., 20, 303306.

Mukherjee, P.K. and Wahile, A. (2006): Integrated approaches towards drug development from Ayurveda and other Indian system of medicines. J. Ethnopharmacol., 103, 25-35.

Nirala, S.K., Bhadauria, M., Mathur, R. and Mathur, A. (2008): Influence of alpha-tocopherol, propolis and piperine on therapeutic potential of tiferron against beryllium induced toxic manifestations. J. Appl. Toxicol., 28, 44-54.
Paget, G.E. and Barnes, J.M. (1964): Toxicity tests. In Evaluation of Drug Activities: Pharmacometrics (eds. Lawrence, D.R. and Bacharach, A.L.), pp.140-161, Academic Press, London.

Pathak, N. and Khandelwal, S. (2006): Modulation of cadmium induced alterations in murine thymocytes by piperine: oxidative stress, apoptosis, phenotyping and blastogenesis. Biochem. Pharmacol., 72, 486-497.

Piyachaturawat, P., Glinsukon, T. and Toskulkao, C. (1983): Acute and subacute toxicity of piperine in mice, rats and hamsters. Toxicol. Lett., 16, 351-359.

Rizvi, S.I. and Luqman, S. (2002): Anti-oxidative property of capsaicin. Med. Chem. Res., 11, 301-307.

Shah, A.H., Al-Shareef, A.H., Ageel, A.M. and Qureshi, S. (1998): Toxicity studies in mice of common spices, Cinnamomum zeylanicum bark and Piper longum fruits. Plant Foods Hum. Nutr., 52, 231-239.

The Ayurvedic Formulary of India, Part II (2000): The Controller of Publications, Ministry of Health and Family Welfare, Government of India. 